\title{
The effects of hypoxia on an information-reduction task in humans'
}

F. LEDWITH, SCHOOL OF SOCIAL SCIENCES, THE FLINDERS UNIVERSITY OF SOUTH AUSTRALIA, Bedford Park, South Australia 5042

Three groups of 10 university students each were tested an a cognitive task of "information-reduction" at ground level, 7,000 ft or 14,000 ft equivalent altitude in a decompression chamber. The task involved three levels of difficulty of transformation of digits read out. The Ss were tested once after 20 or 50 min exposure to the condition set and given no prior training on the task. The two more difficult tasks showed significant linear decline with altitude but the easiest task showed no change.

A recent survey of the psychological literature on the effects of hypoxia (oxygen deprivation) (Tune, 1964) has suggested that studies in this area have failed to take advantage of recent developments in testing techniques in the area of general psychology. Further, Poulton (1966) has pointed out a defect in the experimental design typically used in hypoxia studies: the harmful effects of any stress, including hypoxia, may be masked where Ss are given practice on the task used prior to any exposure to stress. He draws examples from a number of stress conditions to demonstrate this point including a study on hypoxia by Denison, Ledwith, \& Poulton (1966) who found impairment of choice RT at $5,000 \mathrm{ft}$ of altitude. This is a much lower level than expected on the basis of pre-testing designs from which it is generally concluded that no impairment occurs below $10,000 \mathrm{ft}$ of altitude (Luft, 1961).

The experiment reported here was designed to take account of these criticisms. It was decided to test the effects of hypoxia without non-stressed pre-test practice and to use a task devised by Posner (1962) in studying the cognitive processes involved in information-reduction tasks with varying degrees of mental work. The task measures variations in an important area of cognitive activity and affords precise measure of the degree of work load.

Method. Lists of eight numbers (each number drawn at random from an array 1-64) were played back to Ss through earphones at the rate of 30 per $\mathrm{min}$. The Ss were required to do one of three tasks. (1) Record the numbers. (2) Classify each number as an " $A$ " (greater than 32 and odd or less than 32 and even) or a "B" which is the converse of "A." (3) Record the sum of each successive pair of numbers 1 and 2,2 and 3, etc. Task 1 is the easiest task and Task 2 the most difficult task used by Posner representing zero and 40.32 bits information-reduction, respectively, from input to output where the total input is 48 bits ( 6 bits for each of 8 numbers). Task 3 cannot be measured on the same scale of information-reduction and was not used by Posner (1962) but represents an even greater complexity of task involving information reduction and storage on the input simultaneously.

The Ss were 30 volunteer first year psychology students aged 18-26 years and included 14 females. Hypoxia was induced by reducing the air pressure inside a decompression chamber and three conditions were used: ground level, 7,000 ft, and 14,000 ft equivalent altitude. Ten Ss were assigned at random to each condition and tested once. They were tested in pairs on a number of tasks including the one described here and in this task one $S$ of each pair was tested after $20 \mathrm{~min}$ and the other $S$ after $50 \mathrm{~min}$ exposure to the altitude used, following a $7 \mathrm{~min}$ ascent. Care was taken to ensure that Ss were given no information as to what altitude was used and a dummy ascent and descent was used for the ground level group.

Each $S$ heard 12 lists of eight numbers and was required to perform the same task to a pair of lists in the order: Task $1,2,3,2,3,1$, the whole testing occupying approximately $10 \mathrm{~min}$.

Results and Discussion. Figure 1 shows the mean percentage correct answers for the $10 \mathrm{Ss}$ at each pressure level. Task 1 was unaffected by altitude. Tasks 2 and 3 deteriorate with altitude. Trend analysis of Tasks 2 and 3 alone gives an $F$ test of linear trend of $8.67(\mathrm{df}=1 / 24, p<.01)$. Performance on Task 3 was significantly poorer than Task $2(p<.01)$, but there was no

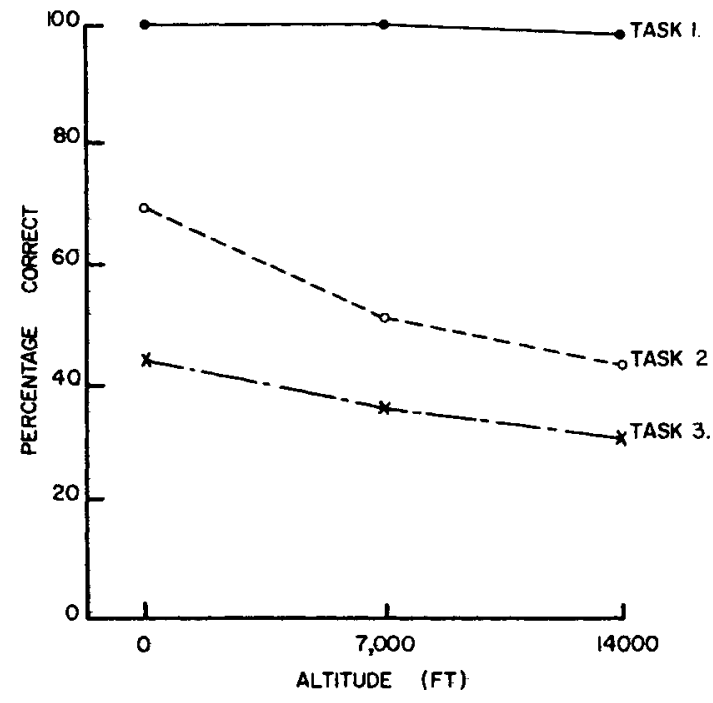

Fig. I. 3 information reduction tasks af 3 levels of altitude.

evidence of interaction with hypoxia. The Ss tested after $50 \mathrm{~min}$ exposure were slightly better than those tested after $20 \mathrm{~min}$ $(p<.1)$, but there was no evidence of interaction with hypoxia (interaction $\mathbf{F}<1$ ).

The results obtained here on the effects on performance of increasing altitude agree with those found for choice reaction time using a more limited range of altitudes (Denison, Ledwith, \& Poulton, 1966). In both experiments performance deterioration was found at the lowest altitude used and the general trend was found to be linear for the discrete levels used. A linear deterioration from ground level is at odds with the bulk of the literature but in both experiments showing this effect hypoxic Ss were given no experience of the task prior to their exposure to hypoxia. This suggests that demonstration of impairment in mild hypoxia requires a particular experimental design.

Ledwith \& Denison (1964) showed that a group at $8,000 \mathrm{ft}$ equivalent altitude was significantly poorer in complex RT than controls, but they rapidly improved with practice so that at the end of $10 \mathrm{~min}$ they were no slower than the controls. Hence, this demonstrated that impairment at low altitude may disappear with practice. Further, even with this form of design, the effects of hypoxia vary with the task used even in the same Ss (Ledwith, 1968). What can be concluded is that the use of different groups of human Ss at different levels of hypoxia without pretraining clearly indicates that there are changes in cognitive capacity at levels of hypoxia previously thought to produce no effect.

The task used seems to be a useful tool in studying the effects of hypoxia. The range of difficulty given numerical specification by Posner (1962) seems adequate to explore in detail the interaction between hypoxia and level of difficulty of the task since Task 1 produced no deterioration and Task 2 marked deterioration under hypoxia. The area within these limits could profitably be studied using the numerical scale of difficulty outlined by Posner (1962).

\section{REFERENCES}

DENISON, D. M., LEDWITH, F., \& POULTON, E. C. Complex R.T. at simulated cabin altitudes of 5,000 feet and 8,000 feet. Aerosp. Med., 1966, 37, 1010-1013.

LEDWITH, F. The effects of hypoxia on performance. Submitted doctoral dissertation, The University of Adelaide, May, 1968. 
LEDWITH, F., \& DENISON, D. M. Complex reaction times at a simulated cabin altitute of 8,000 feet. Report No. 284, 1964, R.A.F. Institute of Av. Med.

LUFT, V. C. Altitude sickness. In H. G. Armstrong (Ed.), Aerospace medicine. London: Bailliere, Tindall \& Cox, 1961. Pp. 120-142.

POSNER, M. I. An information approach to thinking. Air Force Office of Scientific Research Report No. 2635. ASTIA Document 276136, 1962.
POULTON, E. C. Engineering psychology. In Annu. Rev. Psychol, 1966, 17. TUNE, G. S. Psychological effects of hypoxia: Review of certain literature from the period of 1950 to 1963. Percept. mot. Skills, 1964, 19, 551-562.

\section{NOTE}

1. This research was in part supported by a grant from The Reserve Bank of Australia. 